\title{
FRAGMENTOS RIBEREÑOS AL MARGEN DE LA CIUDAD. Propuestas metodológicas para el Estudio de procesos socio-espaciales en el territorio periférico y ribereño de la ciudad de Corrientes, Argentina.
}

\author{
María Florencia Rus \\ Universidad o Institución a la que pertenece: Instituto de Investigación y Desarrollo en Vivienda (IIDVi). \\ Universidad Nacional del Nordeste. Becaria Doctoral UNNE-CONICET. \\ Director de la tesis en curso o de la investigación: Laura Alcalá. \\ maflorenciarus12@gmail.com
}

\begin{abstract}
RESUMEN
Las franjas urbanas ribereñas de la ciudad de Corrientes, Argentina, son territorios de gran heterogeneidad en su configuración y con una marcada desigualdad en las condiciones urbano-ambientales y sociales; constituyéndose como espacios periféricos y marginales de la ciudad. Son a su vez puntos dicotómicos de amenazas y oportunidades, por las constantes crecidas del río que expone a sectores vulnerables, por sus condiciones paisajísticas interesantes al mercado inmobiliario, por el funcionamiento del río como un recurso de producción o de subsistencia. Se convierten en ámbitos de disputa, pasibles a procesos de territorialización y desterritorialización frente a esferas de actores en desigualdad de posibilidades y competencias. El objetivo de esta investigación es contribuir al conocimiento sobre las dinámicas de producción de suelo y los procesos socioespaciales de estos territorios al margen de la ciudad y al frente del río. El trabajo expone los planteamientos metodológicos iniciales y avances preliminares conceptuales, contextuales y de casos análogos de estudio.
\end{abstract}

Palabras clave: Ribera, Periferia, Fragmentación urbana.

\begin{abstract}
The riverside areas of the city of Corrientes, Argentina, are territories of great heterogeneity in their configuration and with marked inequality in the urban-environmental and social conditions; constituted in many cases as peripheral and marginal spaces in the city. They are dichotomous spaces of threats and opportunities, because of the river flooding, their landscape interesting conditions to the housing market, the functioning of the river as a resource of production, of subsistence. They turn into areas of dispute, sensitive to processes of territorialization and deterritorialization opposite to actors' spheres into inequality of possibilities and powers. The aim of this investigation is to contribute to the knowledge on the dynamics of urban production, and the socio-spatial processes of these complex territories. The work exposes the initial methodological approaches, the preliminary advances of concepts, data of context and analogous cases of study.
\end{abstract}

Key words: Riverside, Perifhery, Urban Fragmentation. 


\section{INTRODUCCIÓN}

Se exponen en el presente trabajo los avances realizados en el marco de una beca UNNE-CONICET ${ }^{1}$ y los planteamientos metodológicos iniciales que guiarán la tesis de la Maestría en Urbanismo, $U_{N C^{2}}^{2}$. Se propone estudiar las configuraciones territoriales existentes en sectores urbanos ribereños de la ciudad de Corrientes, Argentina. La temática se sitúa como parte de procesos regionales, situaciones análogas en las diferentes ciudades costeras de la Cuenca del Plata. La costa sobre el caudaloso río Paraná se presenta históricamente bajo la dicotómica condición de oportunidad y riesgo, y en el caso de Corrientes se han seguido procesos históricos diferenciados de ocupación y urbanización, siendo aprovechada para la actividad portuaria, industrial, fines socio-recreativos, desarrollos inmobiliarios, actividades de subsistencia (producción social de la vivienda, pesca, olerías, etc.)

Esto ha producido áreas ribereñas en donde coexisten realidades divergentes, algunas cualificadas por el accionar del Estado con una reconfiguración paulatina de usos; y otras (en su mayoría), se han desarrollado como espacios periféricos en áreas de bañados, atrás de las avenidas que estructuran la ciudad. Son sitio de asentamientos informales con problemáticas ambientales y conflictos sociales, en coexistencia con barrios de vivienda estatal, recintos industriales y empresariales. En este sentido, la heterogeneidad de situaciones urbano-ambientales y sociales de estas costas otras, parecen manifestar internamente y en relación con la ciudad, específicas (y múltiples) condiciones de aislamiento y fragmentación.

En los últimos años se observan dos tendencias: por un lado, la permanencia de asentamientos históricos cuya población tiene en el río su medio de subsistencia, que no llegan a consolidarse integralmente por la vulnerabilidad de su localización sometida periódicamente a las crecientes del río, a pesar de algunas intervenciones provenientes de organismos estatales $\mathrm{y}$, por otro, la relocalización involuntaria de asentamientos ubicados en los sectores donde el Estado ejecutó obras defensivas y proyectos urbanos de espacio público como la Costanera Sur o que corren riesgo de serlo por la presión silenciosa que ejerce el mercado inmobiliario.

En este contexto, el tema de tesis propuesto plantea el estudio de una problemática compartida por los territorios urbanos del agua de la Cuenca del Río de la Plata. Nos preguntamos, ¿Cuáles son las dinámicas de producción de suelo de estas áreas? ¿Qué procesos de configuración territorial se manifiestan y cuáles son sus especificidades en relación con "otras costas" locales/regionales? y en este sentido, ¿qué universo de actores intervienen en la conformación de estos territorios?

\section{ALGUNOS PRESUPUESTOS PRELIMINARES}

Se parte una serie de presupuestos, a modo de grandes cuestionamientos que guían la investigación:

Por un lado, se piensa que el estudio y la acción focalizada en los asentamientos o desde recortes barriales, no permite conocer los fenómenos urbanos presentes en las áreas costeras y tampoco superar las condiciones generales de vulnerabilidad ambiental, socioeconómica y habitacional. Se requiere de diagnósticos integrales que contemplen diferentes escalas de estudio, que, por un lado, trasciendan los límites barriales y promuevan nuevos mecanismos de gestión adecuadas a las coyunturas locales; y por el otro, estén atentos a las lógicas comunitarias existentes. Los déficits y conflictos socio-urbanos requieren para su superación, de la interpretación de los espacios fronterizos y de interrelación entre los distintos fragmentos urbanos, por lo que las áreas de observación y actuación deben ser delimitadas conforme a nuevos criterios a desentrañar en la misma investigación. Dicho de otra forma, se requiere encontrar escalas adecuadas que permitan ir (de)construyendo los límites que existen entre las distintas áreas y abordar la complejidad del territorio.

Otro presupuesto considera que estos territorios se manifiestan como una gran periferia con condiciones de criticidad similares; pero, donde a su vez las diferentes formas de producción del suelo y formas de habitar convierten a estos territorios y sus espacios liminales en periferias múltiples. Esta cuestión puede develarnos diferentes formas de fragmentación socio-espacial. En este sentido, es necesario a su vez, abocarnos a la comprensión de las lógicas de los actores que participan de la construcción del territorio.

\footnotetext{
${ }^{1}$ Beca Doctoral UNNE-CONICET denominada "Criterios y estrategias de Actuación en el Espacio Público de áreas urbanas costeras vulnerables y críticas", que forma parte del PI SGCYT 16C003 "Caracterización urbano ambiental de áreas deficitarias críticas", ambos proyectos dirigidos por la Dra. Arq. Laura Alcalá.

2 Temática estudiada en el marco de la Maestría en Urbanismo de la Universidad Nacional de Córdoba, y que posteriormente será profundizada y abordada a través de la Tesis Doctoral, del Doctorado en Arquitectura de la Universidad Nacional de Rosario.
} 
Se cree, a su vez, que el paisaje de la periferia ribereña ${ }^{3}$ posee condiciones propias y complejas, donde las circunstancias de vulnerabilidad multidimensional suponen necesariamente actuaciones para mejorar la calidad de vida de los habitantes, pero que generalmente se enfocan en acabar con la conflictividad, modificando el patrimonio cultural propio de quienes habitan allí y, por lo tanto, destituyendo los procesos comunitarios preexistentes. Las estrategias que reorganizan el espacio físico y simbólico de la periferia, y sobre todo del borde costero, suelen atravesar o atraer intereses de los sectores del capital inmobiliario en orden de extraer de ellas potenciales plusvalías, sometiendo el espacio vecinal a la disciplina del valor de cambio. Existen contradicciones implícitas entre los objetivos de estos procesos: promover el espacio público y la accesibilidad a la costa - mejorar la calidad de vida de las comunidades existentes, donde corrientemente estas contradicciones se evidencian a través de procesos especulativos, expulsivos o gentrificantes; que a partir de proposiciones y acciones de actores hegemónicos se contribuye a mayor fragmentación y exclusión.

Frente a estos cuestionamientos, el objetivo es contribuir al conocimiento sobre las dinámicas específicas de producción de suelo de estas áreas, sus problemáticas y patrones de configuración territorial ${ }^{4}$, para repensar estrategias metodológicas de construcción de diagnósticos integrales, indagando en criterios de actuación posibles desde dos intenciones muchas veces no compatibles en las líneas de actuación en estos territorios: volver accesible el río al resto de la ciudad y, además, superar las condiciones de vulnerabilidad y exclusión de los pobladores existentes. Esto, requiere revisar criterios y posibles instrumentos que sirvan a la cualificación de los espacios urbanos desde las lógicas de los actores que habitan estos territorios, evitando caer en procesos expulsivos, fragmentadores o gentrificantes, y regulando las tendencias privatizadoras del borde ribereño.

\section{PROPUESTA METODOLÓGICA Y ALGUNAS NOCIONES CONCEPTUALES:}

Se propone una metodología cualitativa, que, desde un enfoque multiescalar y multidimensional, pretende abocarse al estudio de áreas testigo, interpretando los procesos territoriales con distintas instancias de aproximación a su complejidad. Se buscará a lo largo de todo el proceso un abordaje dialéctico entre la práctica o el proceso de conocimiento sobre el territorio ${ }^{5}$ y el abordaje conceptual de diferentes teorías; siguiendo a Harvey (1973) en su afirmación de que la teoría debe ser práctica.

Se parte de una primera etapa, de carácter conceptual que buscará comprender y contextualizar la temática en el marco de un cuerpo teórico que dé lugar a discusiones y reflexiones, tanto como en la revisión del estado del arte o de la controversia. En esta etapa y a lo largo de diferentes instancias en la investigación, se estudiarán casos análogos con el fin de conocer áreas costeras en el contexto regional, estudiando los patrones de configuración territorial existentes e indagando en los procesos de renovación urbana que se han ido produciendo en función de actores públicos, privados o mixtos.

La segunda etapa de la investigación es de tipo exploratoria y se detendrá en la descripción, interpretación y representación de las áreas costeras urbanas, a través de un enfoque diagnóstico buscando conocer las dinámicas de crecimiento de la ciudad en relación con su paisaje fluvial.

Esta etapa se divide en una primera Instancia, dedicada a comprender los procesos urbanos en general que se desarrollaron en la Ciudad de Corrientes, en relación con su localización y al crecimiento territorial y demográfico; así como también, aspectos vinculados a la metropolización del área Gran Corrientes- Gran Resistencia insertos en el contexto regional y nacional. Se pondrá especial atención a procesos recientes y sus derivaciones como la construcción de la Costanera Sur; o el actual desarrollo del Máster Plan de Santa Catalina. Para hacerlo se utilizará información secundaria proveniente de organismos públicos y de trabajos de investigación preexistentes. Y en segunda instancia, se seleccionarán dos áreas costeras: una en la zona norte y otra en la zona sur para su estudio en profundidad. Ya se cuenta con una delimitación de estas en base a las características identificadas en trabajos previos, bajo la definición que Barreto y otros (2014) hacen de áreas urbanas deficitarias y críticas (AUDC). Áreas donde se reconocen sectores y barrios homogéneos internamente y diferentes entre sí en cuanto a su situación habitacional, que comparten condiciones comunes

\footnotetext{
${ }^{3}$ El paisaje hace referencia al enfoque socioambiental proveniente de la geografía, como una herramienta conceptual y metodológica para conocer y transformar el territorio, ya que confluyen elementos tanto físicos como socio-culturales a tener en cuenta para el conocimiento del territorio. El territorio en este sentido aparece como "una unidad espacial socialmente moldeada y vinculada a las relaciones y escalas de poder". (Raffestin, 1989; en Lobaton, 2015, p. 86) como en este caso nos interesan ambos conceptos hablamos de "paisajes territorializados". (Lobatón, 2015)

${ }^{4}$ Los patrones de configuración territorial son definidos como procesos y dinámicas característicos y que se repiten en el ámbito de la periferia de las ciudades, que hacen a las condiciones de criticidad y prioridad para la gestión pública: vulnerabilidad socio-económica, conflictividad social, aislamiento, fragmentación, segregación socio-espacial. (Alcalá y otros, 2016)

${ }^{5}$ Nos interesa la distinción realizada por Lobaton (2014) entre paisaje y territorio. El territorio aparece como unidad espacial socialmente moldeada y vinculada a las relaciones y escalas de poder, pero que desde su relación pueden convertirse en "paisajes territorializados", para estudiar relacionalmente el moldeado sociocultural, el geosistema existente y el entramado de escalas y dominios políticos (p. 86)
} 
de localización y accesibilidad, vulnerabilidad y riesgo hídrico, déficit de servicios y equipamientos, y distintos tipos de conflictividad social. ${ }^{6}$

Las áreas preseleccionadas, en las Franjas Costeras Norte y Sur responden a áreas de bañados, y serán tomadas como modelos de estudio y comparación. Estos recortes espaciales, que escapan tanto al polígono de barrio como al plan urbano de gran escala. Dentro de este proyecto se propone estudiarlas desde dos escalas metodológicas de abordaje:

- MACRO-ANALÍTICA (Mera, 2014) donde será importante el reconocimiento de múltiples aspectos físicos, urbanos y ambientales. Se identificarán Unidades Residenciales Espaciales Homogéneas (UERH), condiciones del sistema de conectividad y accesibilidad, la estructura del sector en cuanto a tramas, continuidades, barreras; el espacio público y las formas de uso comunitario; dotación de servicios e infraestructura (Alcalá y otros, 2016). Esta información se obtendrá a partir de la observación directa y de información del Municipio, institutos provinciales y de las empresas prestatarias de servicios Además, se considerará la situación sociodemográfica y económica de los barrios del área en base a información municipal, censal (Censo y Encuesta Permanente de Hogares EPH ) y catastral; así como normativas existentes que determinen aspectos urbanos y ambientales, como límites administrativos, zonificaciones en base al Código de Planeamiento Urbano vigente, etc. Se construirán mapas temáticos georreferenciados para representar toda la información obtenida. Como plantea Corboz, (1983) los mapas se trazan, construyen como una interpretación propia del territorio. Estudiar, dibujar e interpretar permite conocer los diferentes procesos que confluyen en el territorio como ser: las actividades productivas activas o caducas, las urbanizaciones cerradas, las formas informales de producción, la precariedad del hábitat, las irregularidades en los usos el suelo.

- MICRO-ANALÍTICA tiene como objetivo un análisis más cercano a ciertos sectores seleccionados y considerados como prioritarios frente a las condiciones de criticidad y la ausencia de información actualizada, focalizándonos en un estudio historiográfico y situacional, a partir de técnicas etnográficas. En este caso, se propone un trabajo de indagación sobre aspectos cualitativos como percepciones del barrio, relación con el paisaje, delimitación de sectores internos o externos, barreras, estigmatizaciones; conflictos socioespaciales, dificultades y fortalezas, que sean percibidos por los vecinos o referentes barriales a partir de entrevistas en profundidad y mapeos colectivos. Complementariamente, se utilizará información proveniente de la observación directa de las actividades llevadas adelante por la Red Vecinal Zona Norte; así como involucrar el conocimiento proveniente de organizaciones como: la Cruz Roja, TECHO, Juntos a la Par, Mas Voces, etc. Esta última escala, vinculada mayormente al estudio del conjunto de actores que participan en la construcción de ciudad, los conflictos y relaciones socioespaciales, está prevista a ser abordada con mayor profundidad en una instancia posterior de Tesis Doctoral como continuación y profundización de la temática abordada en la tesis de maestría.

Por último, la etapa conclusiva buscará delinear criterios de actuación en función de conflictos y espacios de oportunidad identificados, desde sus diferentes escalas y dimensiones; y elaborar pautas de gestión y políticas que puedan acompañar los criterios de intervención propuestos.

\section{CORRIENTES: CRECIMIENTO Y VINCULACIÓN CON EL RÍO.}

Corrientes es una ciudad localizada al noreste de la Argentina, sobre el margen izquierdo del río Paraná y cercano a la confluencia de este con el río Paraguay. Posee 385.726 habitantes (según datos del INDEC del último censo 2010). Su morfología fue históricamente condicionada por su condición ribereña, en donde el rio jugó diferentes roles: para los pueblos originarios como vínculos de unión y comunicación dentro de la vastedad territorial, luego, como red de avanzada del proceso de colonización de los españoles o como un recurso de producción conectado al sistema de reducciones jesuíticas. Los territorios del río, a su vez, funcionaron como espacios fronterizos de conflictos donde se libraron múltiples batallas en las luchas por el territorio. (Diagnóstico de Santa Catalina, 2014)

La ciudad de Resistencia se funda en el año 1878, sobre una antigua colonia forestal para promover la radicación de nuevos contingentes migratorios. Se comienza a ocupar el territorio al otro lado del río y durante

\footnotetext{
${ }^{6}$ El concepto de Área Urbana Deficitaria Crítica surge del marco teórico del equipo de investigación donde se participa. Sirve para recortes exploratorios que buscan encontrar escalas intermedias para estudiar áreas que son parte del territorio inacabado, dependiente, diverso de la periferia donde se producen los nuevos patrones contemporáneos de configuración territorial (fragmentación, segregación, conflictividad social, aislamiento). Entendiendo que las problemáticas urbanas actuales dependen más de medidas estructurales y de estrategias políticas coyunturales; el estudio de estos territorios intermedios de conflictos permite percibirlos como áreas prioritarias de análisis y focalización en los procesos de redistribución de recursos, intentando reducir las inequidades socio-urbanas.
} 
muchos años este funcionó como un límite en la relación entre ambas ciudades, consolidándose cada una como capital de provincia. La finalización del puente General Belgrano en 1973 fortaleció relaciones, paulatinamente conformando un nuevo escenario geopolítico, posicionándose ambas ciudades como nodos estratégicos que funcionan de manera conjunta; por un lado, con sus especificidades legales, institucionales y administrativas propias, muchas veces dispares; y por el otro, con cada vez mayores flujos laborales, educativos, recreativos.

La estructura urbana de Corrientes surge del damero fundacional, expandiéndose de forma concéntrica en sus inicios, siempre siendo el río un límite o estructurador. El crecimiento fue de forma radial hasta la década de 1940, consolidándose el casco histórico. A partir de ese momento comenzaron a producirse diferentes obras de infraestructura como la Av. 3 de abril, eje donde se encontraba el primer ferrocarril y que había sido históricamente una barrera de crecimiento hacia el sur. Los diferentes barrios habitacionales de promoción estatal (sobre todo de tipología FONAVI) comenzaron a localizarse hacia el sur, y la ciudad fue creciendo en sentido perpendicular a la costa.

En esa misma década se construyó una defensa y avenida con paseo junto al río, actual Costanera Gnral. San Martín. Entre los 50' y 60' se definieron las vías estructurales de la ciudad: Av. Pujol, Maipú y se entubó el Arroyo Poncho Verde. El crecimiento a modo de abanico hacia el territorio configuró cada vez mayores expansiones hacia el interior, desvinculándose la planificación de las otras áreas costeras, las cuales se abordarán más adelante.

Es posible decir que la ciudad de Corrientes, como tantas otras urbes de la región, fue el resultado histórico de operaciones basadas en intereses económicos y geopolíticos, desarrollados a partir de instrumentos como la cuadrícula, la propiedad privada, el zonning, los planes directores. Como fue relatado, la expansión urbana se extendió a partir de la trama ortogonal central y a lo largo de los principales ejes o vías de conexión y transporte de forma disgregada imponiéndose a un territorio natural particular, marcado por las dinámicas cambiantes del agua, recurso en abundancia y por su planicie infinita, que, postergado en los procesos de planificación, se convirtió en "obstáculos" o en "barreras a salvar" en la construcción de ciudad.

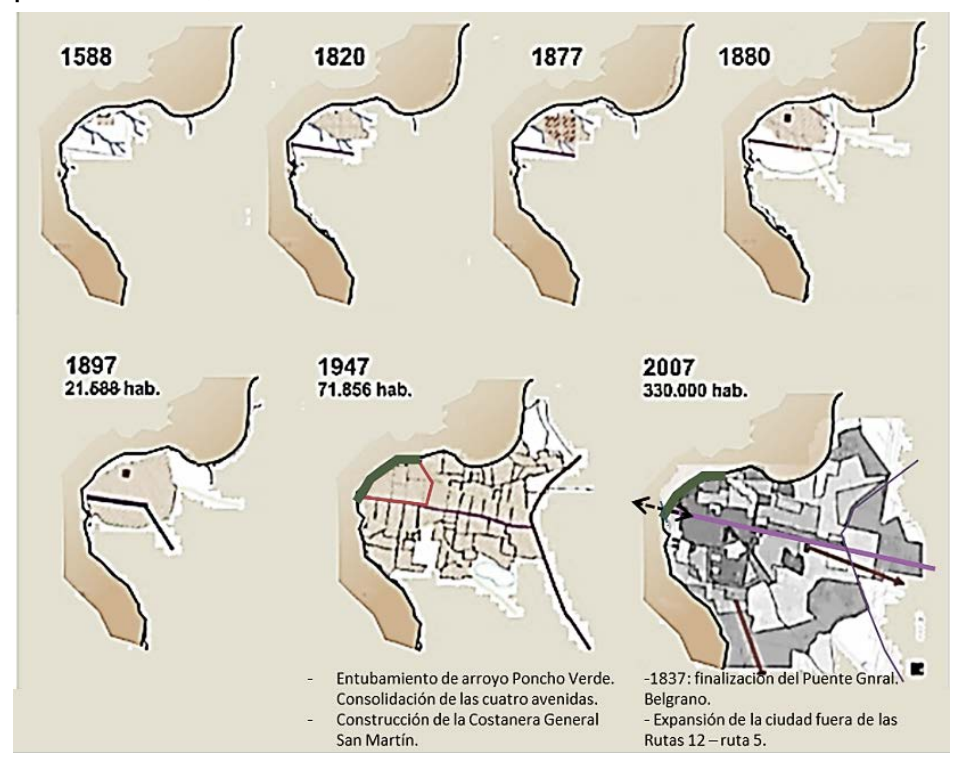

Esquema del crecimiento de la Mancha Urbana de la Ciudad de Corrientes. Fuente: Diagnóstico Master Plan Santa Catalina, 2014.

Como se mencionó al principio, el río es un componente primordial que condiciona y participa de las formas de configuración de la ciudad obteniendo históricamente diferentes significados y valores como parte del paisaje cultural. En este sentido, es importante rescatar como la concepción del valor y la utilidad de elementos que forman parte del patrimonio no significan lo mismo para las diferentes comunidades o grupos. Para algunos la tierra al frente del río puede significar una mercancía y para otros un medio de subsistencia, y en este sentido evocamos a los que Bonfil Batalla (1998) refiere cuando habla de que no hay patrimonios culturales comunes, como no hay culturas homogéneas en una ciudad o Estado. Refiriendo el autor a las formas históricas de colonización del otro establecidas en nuestra cultura occidental, desde lecturas hegemónicas sobre las formas de transformar o interpretar el paisaje.

\subsection{El territorio natural de implantación y el avance sobre áreas de riesgo hídrico.}


Como fue anteriormente mencionado, la ciudad comparte condiciones ambientales análogas a gran parte de las ciudades emplazadas en el territorio de la Cuenca del Plata, con situaciones íntimamente ligadas a las crecientes periódicas de los ríos y a regímenes pluviales de clima subtropical, en una topografía plana con un sistema fluvio-lacustre que surca el territorio y lo modifica. Tres elementos son decisivos en esta configuración: el relieve con sutiles variaciones de nivel (correspondiente a la llanura Chaqueña y a la Mesopotamia); la cuenca hidrográfica con su complejo sistema de ríos, arroyos, lagunas, humedales; y los regímenes de lluvias que van de 1000 a 1500 mm anuales. Se trata de ríos que pueden variar hasta casi cuatro veces su caudal, como consecuencia fundamentalmente de lluvias producidas en su cuenca alta. El río Paraná, por ejemplo, puede variar de $17.000 \mathrm{~m} 3 / \mathrm{s}$ a $60.000 \mathrm{~m} 3 / \mathrm{s}$.

El Área metropolitana de Corrientes se encuentra en condiciones favorables con relación a su vecina, el Gran Resistencia, implantada en gran parte dentro del valle de inundación del Río Paraná. ${ }^{7}$ Corrientes, en cambio, se encuentra a una cota más alta, y en sus encuentros con el río existen perfiles más acentuados o terrazas, que más allá de sus procesos erosivos y modificaciones por las crecidas, se consolidan como límites.

Por otro lado, el territorio también plantea sus especificidades naturales hacia donde la urbanización ha ido avanzando y transformándolo. Predominaron prácticas basadas en procesos de trasformación y dominación entre las que se identifican:

- El entubamiento de antiguos arroyos en el centro de la ciudad: el centro histórico de la ciudad se originó entre medio de diferentes arroyos, que en diferentes momentos fueron modificados y entubados, sin embargo, sus trazas aún subsisten por debajo de la calzada y se manifiestan en inundaciones causadas por las deficiencias del drenaje pluvial (González, 2015). Contreras (2015) explica que los valles de estos arroyos permanecen activos, funcionando como grandes desagües, que, sumado al proceso de impermeabilización de las áreas centrales, al encauzamiento producido por las calles y a la saturación del sistema de desagote, se producen verdaderos torrentes que traen aparejados importantes problemas a la ciudad en la actualidad.

- El avance sobre áreas de bañados al sur de la ciudad se da a partir de la construcción de grandes conjuntos habitacionales antes de 1990 a modo de "ciudades satélites" o "monoblocks", que se localizan en la periferia, y guían el crecimiento hacia este sector, ocupando grandes humedales donde se constituyeron barrios tanto formales como informales, como el B ${ }^{\circ}$ Laguna Seca, Barrio La Olla.

- La ocupación de los bordes ribereños de bañados, áreas bajas y no cualificadas por el accionar del Estado, las cuales son objeto de esta tesis, tuvieron un proceso histórico de conformación de asentamientos populares informales por medio de autoconstrucción (a partir de 1960), como una forma de producción social del hábitat común a nuestras ciudades latinoamericanas. Por otro lado, se localizaron algunos recintos industriales o empresariales y se privatizaron algunos tramos de costa por parte de sectores de mayor renta.

- El Proceso de metropolización dispersa y crecimiento hacia el sistema de lagunas sobre la "Lomada Norte", que constituyó una dinámica de expansión en relación con otras localidades como Santa Ana, Riachuelo, San Luis, etc. Esto se vincula a las posibilidades del mercado de producir barrios cerrados, clubes de campo, viviendas de fin de semana, frente a menores regulaciones. Se observa la ocupación de áreas de humedales o la presencia de lagunas contenidas en las subdivisiones parcelarias, observándose paulatinamente una tendencia a su relleno y desaparición. En períodos de intensas lluvias se registran anegamientos que afectan a gran parte de esta región, como los ocurridos en mayo/junio $2017 .{ }^{8}$

En Corrientes, tanto como en otras ciudades litorales, la tendencia de crecimiento coincide con la inclinación a ocupar o avanzar sobre áreas vulnerables ambientalmente, aprovechando las condiciones generales de protección contra las crecientes del río, y la disposición temporal de suelo libre en períodos secos.

La situación se vuelve más crítica frente a la deficiencia de mecanismos de gestión e instrumentos legales que puedan regular estos procesos: no se cuenta con cartografías de riesgo hídrico, ni con alguna ordenanza que regule los usos de suelo en función de esto; los diferentes organismos que debieran regular estas cuestiones trabajan de forma sectorial y desarticulada (catastro municipal, provincial, Instituto de Vivienda Provincial, Planificación Urbana municipal, Instituto Correntino del Agua y del Ambiente).

\footnotetext{
${ }^{7}$ Si bien el Gran Resistencia y Corrientes conforman un área metropolitana bi-nuclear en relación a su interdependencia de flujos de tipo recreativos, comerciales, educativos, etc.; en cuanto a cuestiones administrativas, normativas y políticas funcionan de manera autónoma. A su vez, presentan condiciones físicas muy diferentes, ya que las áreas urbanizadas de Resistencia se localizan alejadas del Río Paraná y en relación al sistema fluviolacustre del Río Negro, un afluente del anterior. Se incluirán en la tesis una descripción de estas diferencias geográficas en las relaciones con el río. Sin embargo, el objetivo de la tesis es abordar desde una escala menor, los procesos de costas "ocultas" en la Ciudad de Corrientes, donde los conflictos socio-espaciales exigen esta doble mirada micro-macro analítica.

${ }^{8}$ Como se observa en la hipsometría realizada por la Municipalidad de Corrientes, las lagunas de la Lomada Norte poseen una morfología particular y se encuentran a una altura mayor, por lo que durante períodos secos desaparecen y se convierten en suelo de interés inmobiliario. Esto tiene sus implicancias en el resto de la ciudad, afectando las formas de escurrimiento de las lluvias por la impermeabilización del suelo, produciendo inundaciones cada vez mayores en áreas más bajas.
} 


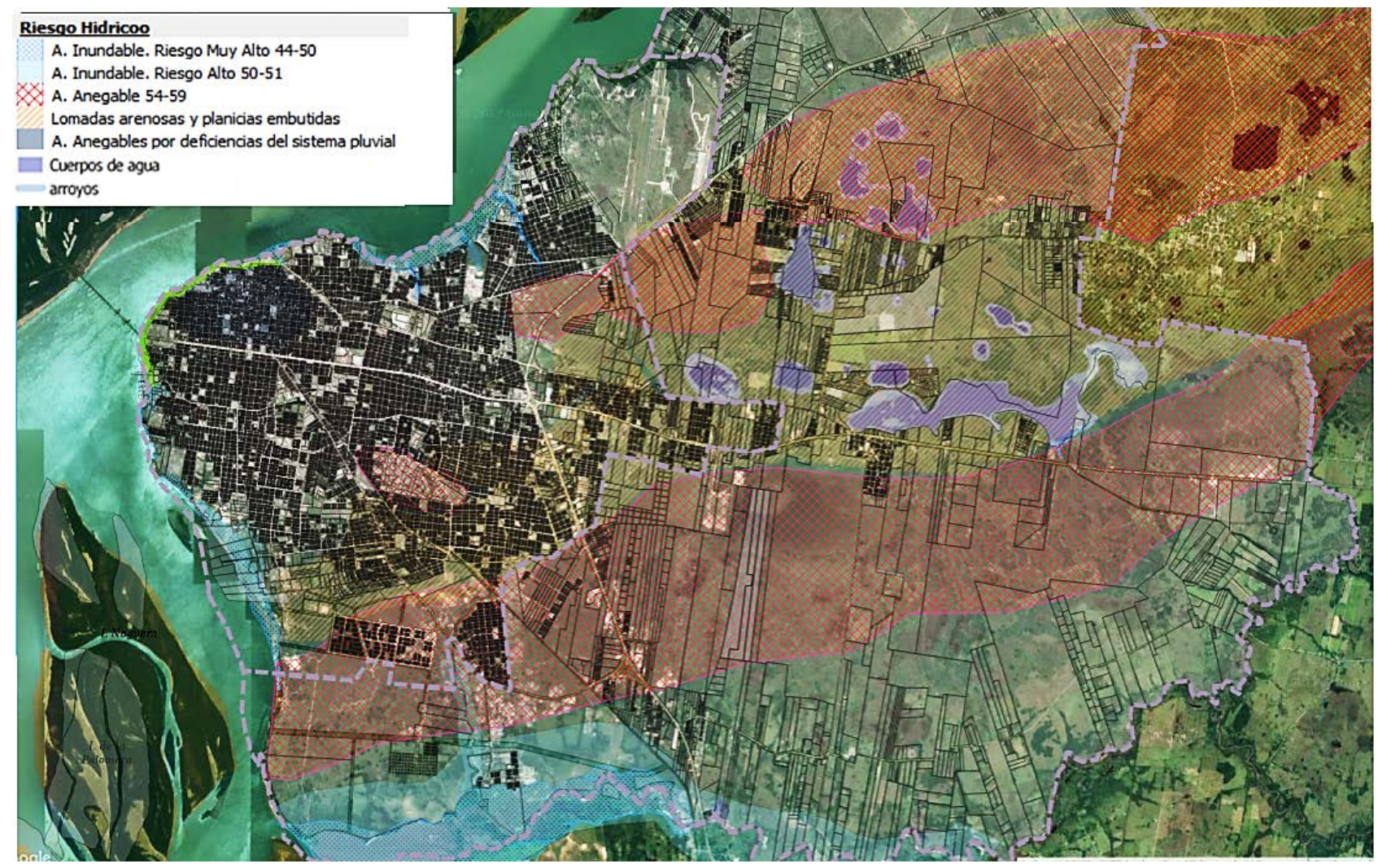

Cartografía tentativa de áreas riesgo hídrico de la ciudad de Corrientes. Fuente: Elaboración propia, en soporte GIS en base al cruzamiento de datos y planos históricos, mapas de elevación, riesgo de anegamiento e inundación y plano urbano catastral, 2017.

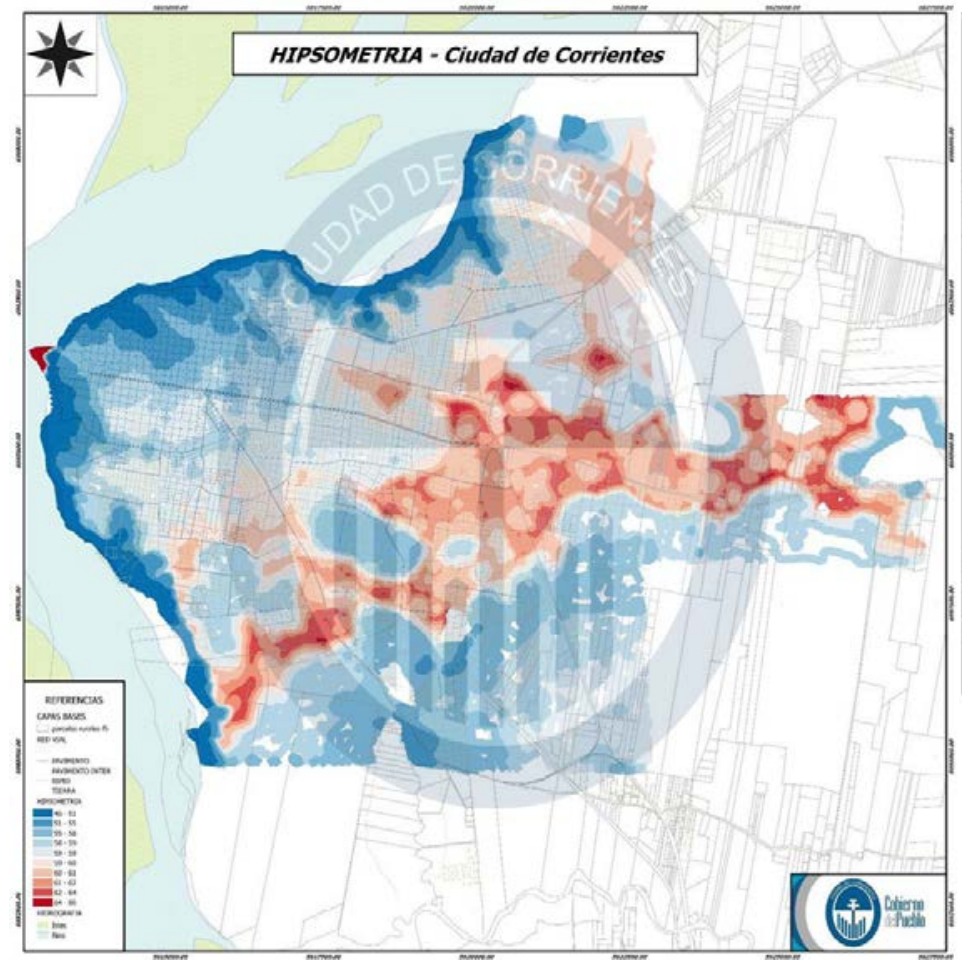

\begin{tabular}{|c|}
\hline REFERENCIAS \\
\hline CAPAS BASES \\
\hline$\square$ pirtelos nurises is \\
\hline GED VML \\
\hline - MVINENTO \\
\hline DVINENTO LITER \\
\hline รากั \\
\hline TIERRA \\
\hline HTPSONETREA \\
\hline$\square+6.51$ \\
\hline$\square 1.55$ \\
\hline 55.58 \\
\hline $58 \cdot 59$ \\
\hline $59 \cdot 59$ \\
\hline $59 \cdot 60$ \\
\hline 60.61 \\
\hline $61 \cdot 62$ \\
\hline ]62.64 \\
\hline$\square$ - $64 \cdot 86$ \\
\hline HIDROCRAFIA \\
\hline 1565 \\
\hline - Mos \\
\hline
\end{tabular}

Mapa Hipsométrico de la Ciudad de Corrientes. Fuente: Relevamiento altimétrico Año 1998 Dirección Catastro Provincial M.D.T. S.I.G. Municipalidad de Corrientes.

\subsection{La ribera correntina: centro-periferia.}


El área central de la Ciudad de Corrientes parte del casco histórico, localizado junto al río. A su vez dio lugar en este radio al puerto y la instalación de ciertas actividades fabriles y portuarias, muy pocas aún persistentes. En la actualidad, el puerto de la ciudad no es tan destacado a nivel nacional ya que su superficie operativa es escasa vinculada, justamente, a su localización céntrica.

Los paseos costeros surgieron como infraestructuras defensivas, de circulación y espacio público, como el caso de la antigua Costanera General San Martín ${ }^{9}$, que permitió consolidar la costa desde el puerto hasta la base del puente, acompañado hacia el interior del territorio de los barrios más antiguos de la ciudad en su mayoría de los sectores socioeconómicos más altos. Este sector, inscripto entre cuatro avenidas, concentra la mejor calidad y cantidad de servicios (comerciales, educativos y administrativos), infraestructuras y las mejores dotaciones de espacios públicos, de los cuales dependen el resto del área metropolitana (tanto como la ciudad de Resistencia).

La reciente avenida costanera y paseo Juan Pablo II, conocida como costanera sur, fue construida entre 1998 y 2008 como una extensión de la anterior, prolongándola unos $900 \mathrm{mts}$. hacia la zona sur de la ciudad. Esta se constituyó como un paisaje que modificó la realidad anterior sustancialmente produciendo un territorio híbrido. Si bien los paisajes pueden ser entendidos como palimpsestos de múltiples capas del transcurrir humano, se considera que este sector tuvo un proceso de sustitución social y cultural conducida, de relocalización y expulsión paulatina de los diferentes asentamientos populares pesqueros y oleros preexistentes. Aunque esta infraestructura es exaltada como un gran "evento" para la ciudad dentro de los discursos ("la joya del Paraná", "volver la vista al río"), y responde realmente a un espacio público de gran calidad y convocatoria, parecen ocultarse los procesos no deseados que fueron desencadenados. Este paisaje planificado, deriva en la cultura que se planea (Bonfil Batalla, 1998).

La costa en este caso es lugar de procesos de desterritorialización y territorialización. Los grandes proyectos urbanos provocan modificaciones en las ciudades que involucran a los actores Estatales y privados como símbolo de competitividad (Lungo y Smolka, 2005). Si bien se convierten en espacios públicos convocantes, colaborando en el perfil turístico y comercial por medio de playas, carnaval, ferias, restaurantes, puestos de comida, etc.; simbolizan muchas veces procesos de exclusión de ciertos sectores, construyendo otras costas atractivas para el mercado inmobiliario y reinterpretando desde las lógicas dominantes los valores que pueden ser atribuidos a los patrimonios culturales. Los atributos tanto paisajísticos como normativos, hacen a una demanda creciente de aquellos que pueden acceder a través de las nuevas formas de habitar: edificios cerrados, torres residenciales exclusivas, vacíos subutilizados; con sus barreras hacia la otra ciudad, los asentamientos informales o barrios de clases bajas, produciendo procesos de fragmentación.

El espacio ribereño aparece como fracciones con diferentes relatos, de "paisajes territorializados" donde se puede observar la disposición segmentada de clases sociales en el territorio y donde se presentan diferentes formas de relación con el río y con la ciudad, determinando goces diferenciados de los recursos y del derecho a la ciudad. Abramo (2012) identifica como propios de las ciudades latinoamericanas "comfusas" (compactasdifusas), tendencias simultáneas y opuestas guiadas por el mercado formal e informal de suelo: la verticalización de sus áreas centrales y la expansión en baja densidad hacia la periferia; la producción de áreas residenciales claramente diferenciables entre sí, por el tipo de urbanización y por los perfiles sociales de quienes las habitan (barrios cerrados, con altos estándares constructivos y alta calidad ambiental, conjuntos de viviendas seriadas, precaria urbanización promovidos por el Estado, asentamientos informales). Con el tiempo, estas ciudades fueron perdiendo la continuidad urbana tradicional, característica de sus tramas regulares fundacionales, por la producción de tramas variadas, discontinuas entre sí. Este es el caso de la periferia, marcada por la creciente desigualdad social y la diferenciación espacial residencial que ha contribuido a la progresiva fragmentación socio-espacial.

Nos preguntamos, entonces, ¿qué ocurre con los barrios atrás de las grandes avenidas y al frente de la ribera que son desconocidos (aún) para la planificación y para aquellos sectores sociales que habitan áreas centrales? Las riberas periféricas, al norte y sur de la ciudad donde los habitantes residen informalmente en bañados, al margen de la ciudad, a su vez pueden ser vistas como frentes por su implantación geográfica y por el lugar que ocupan en los imaginarios urbanos de diferentes grupos. Aparecen nuevos proyectos que desenvuelven en los medios de comunicación las transformaciones posibles a territorios que otros (aquellos que no las habitan) reconocen como vaciados, tanto de comunidades e individuos con historia como de patrimonio construido por estas.

\footnotetext{
${ }^{9}$ Entre 1929 y 1944 la construcción de la obra de defensa de casi 2,5km de longitud para consolidar el borde de la ciudad (del área central), y que consiste en una línea sinuosa que sigue los accidentes geográficos del borde fluvial, que incita al recorrido y permite visuales variables y dinámicas. La obra sirvió además para consolidar la Avenida General San Martín y un sistema de espacios verdes públicos que conforman el paseo costero de la ciudad. Según Valenzuela (2008) este borde es una frontera entre lo natural y lo culturalla ciudad-, es una suerte de cremallera o engranaje donde la ciudad se introduce en el medio natural a través de las puntas, y donde la naturaleza sobre la ciudad en forma de espacios verdes públicos.
} 
Oculta, desconocida, la periferia aparece como espacio urbano, circunstancia y escala geográfica donde se generan mayores procesos de desigualdad. Sin embargo, el territorio de la periferia es pensado casi siempre como un todo genérico, en función de ciertas características: dependencia funcional del centro, carencia de ciertos atributos y actividades de los cuales depende la vida urbana, territorio de crecimiento difuso, en construcción, débilmente vinculado, deficitario en infraestructuras, servicios básicos, equipamientos y calidad de espacio público. Predomina la idea de un territorio inacabado, donde el urbanismo y los gobiernos, experimentarán nuevas formas de residencia urbana, con el fin de superar los principales problemas de la ciudad central, y donde se desarrollarán proyectos para el completamiento, urbanización, costura y cualificación urbanas. (Alcalá y otros, 2016) Para algunos autores, los procesos políticos de la ciudad (y en este lugar la planificación y la obra pública) funcionan presionando y negociando en torno al uso y el control de los "mecanismos ocultos" de redistribución (Wood, 1968; En Harvey, 1973) ${ }^{10}$

La periferia es vista por algunos autores como un espacio "pasivo" (Pintos, 2011) que no produce, solo consume, y algunas veces hasta pierde el carácter complejo social y funcional siendo monopolizadas por la clase rentista, o en el otro extremo, por enclaves de pobreza. Pero también pueden considerarse como "activas", territorios en constante disputa, por la lucha por el espacio urbano, la existencia de un caos aparente (Marcuse, 1997), que puede develarse a partir de la existencia de una sociedad que se organiza espacialmente de acuerdo con una diferenciación socioeconómica y de órdenes claramente establecidos.

Otros autores creen en la existencia de periferias diversas, que pueden remitirse a condiciones y temporalidades muy diferentes, que derivan de los grupos distintos que habitan la ciudad. Según Segura (2010) esta aparece como una experiencia común de condiciones parecidas de deficiencia, pero que en realidad no se traduce necesariamente en una experiencia compartida, punto de articulación entre residentes que llegaron en distintos momentos y con condiciones socioeconómicas desiguales, refiriéndose a la situación legal de la tierra en la que se asentaron, a la inserción en el mercado de trabajo, etc. (Segura, 2010, p. 2) Las diferencias también se vinculan a las expectativas singular y socialmente construidas sobre lo que se tiene y se puede tener, experiencias habitualmente invisibles al resto de la ciudad. Mientras, la ciudad tradicional, con sus barrios consolidados, de identidad y nombres definidos y representativos de lo que se suele entender como patrimonio cultural genérico de lo que es Corrientes, se expande hacia la periferia, donde la delimitación de cada barrio responde a otros procesos de territorialización y a espacios de identidad heterogénea no reconocidos.

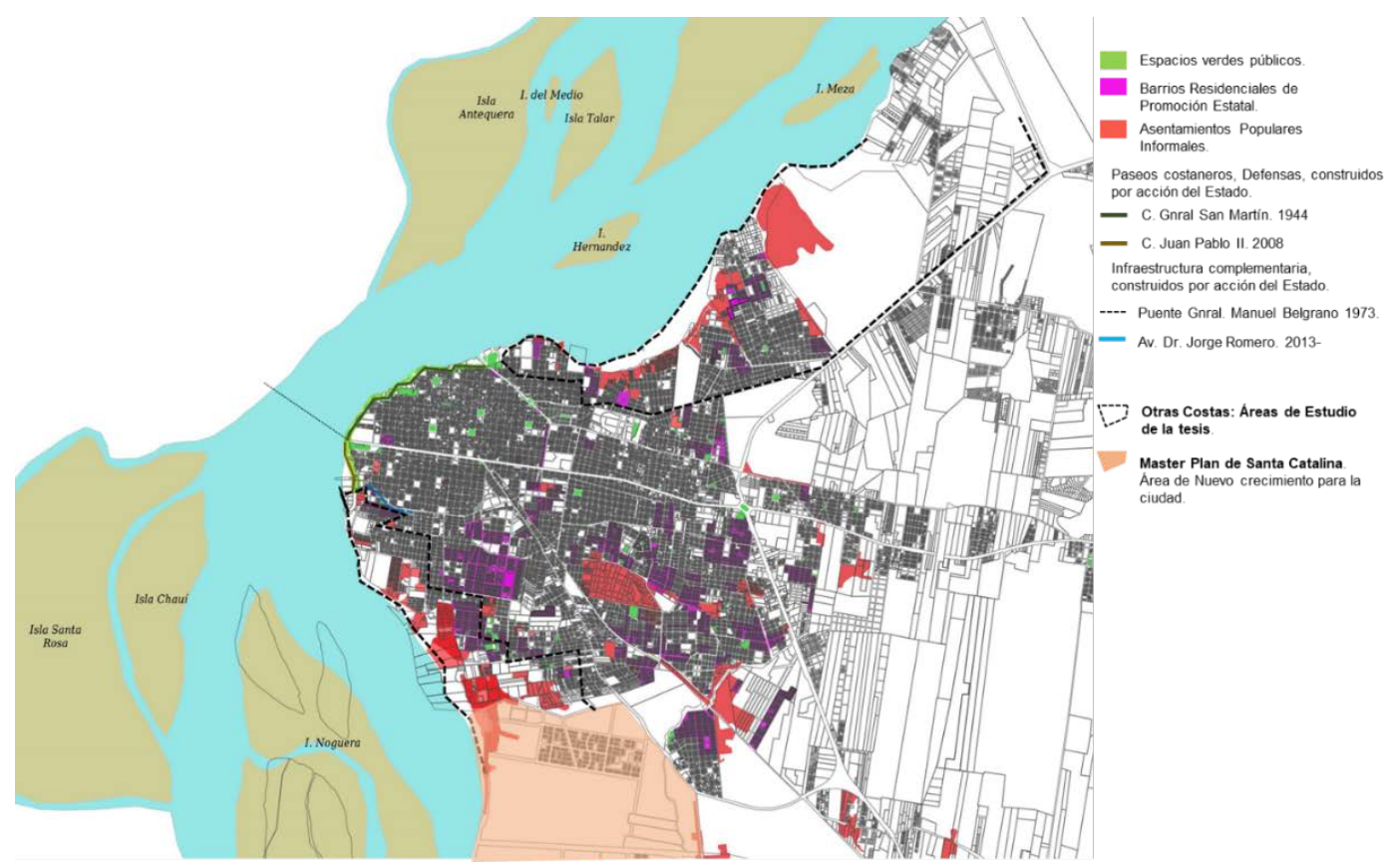

Costas intervenidas y no intervenidas por el Estado y localización de unidades residenciales de promoción estatal e informal. Fuente: Elaboración propia, 2017.

\footnotetext{
${ }^{10}$ Harvey (1973) expone en su libro "Urbanismo y Desigualdad Social" las formas de redistribución de la riqueza o el "ingreso" en un sistema urbano y los actores que participan. En este sentido, expone que "los procesos políticos dentro del sistema urbano deben ser considerados como un medio de distribución de los beneficios exteriores de asignación de costos exteriores" (p. 71), estableciendo como grupos que detentan mayor poder (y son más reducidos) pueden obtener ventajas sobre cualquier otro.
} 


\section{LOS CASOS DE ESTUDIO: LAS RIBERAS NORTE Y SUR.}

Esta tesis adopta como casos de estudio las áreas de bañados localizadas en márgenes ribereñas del río Paraná en la zona Norte y Sur de la ciudad, los cuales son ámbitos desconocidos o contemplados de forma parcial para la planificación. El objetivo, como fue mencionado antes, es desarrollar un proceso de conocimiento y re-conocimiento de los patrones de asentamiento y configuración de estos territorios atentos a las dinámicas de producción de suelo y conflictos existentes. En esta instancia preliminar se avanzó en la comparación de estas áreas con toda la ciudad, a través de algunos indicadores urbano-ambientales: conectividad, situación ambiental, infraestructura básica (agua y cloaca), espacio público, unidades espaciales homogéneas, que puedan ayudarnos a comprender algunas condiciones que afectan a estos barrios o grupos en tanto efectos exteriores, accesibilidad y proximidad. (Harvey, 1973)

\subsection{Situación ambiental}

Como fue mostrado en la cartografía de riesgo hídrico explicada precedentemente, en general, los barrios que se encuentran en los márgenes del río están expuestos a inundaciones, una gran franja se encuentra en una cota de 44-50 msnm y 50-51 msnm, de carácter Inundable Riesgo "alto y "muy alto". (Máster Plan de Santa Catalina, 2014) Los bañados son territorios de morfologías cambiantes por la influencia del río y posee una topografía de barrancas que produce desniveles muy marcados intra y entre barrios.

Existen arroyos internos que surcan y dividen el territorio de forma perpendicular a la costa, confluyendo en esta. Son, en algunos casos, áreas muy críticas ambiental y socialmente como el Arroyo Pirayuí al Sur, o micro-arroyos, como el Santo Domingo en el sector norte. En estos lugares la criticidad está dada por el aumento de la cota hidrográfica que inunda a las viviendas aledañas, por la constante conformación de múltiples basurales que dificultan el escurrimiento, tanto por la densificación residencial a sus alrededores o por funcionar como grandes desagües pluviales de toda la ciudad que transportan grandes caudales; dotando, además de un olor y aire tóxico constante. Auyero (2008) nos recuerda que muchas veces no es tenido en cuenta en las etnografías de la pobreza en América Latina que los pobres no respiran el mismo aire, no toman la misma agua, ni juegan en la misma tierra que otros.

Otras situaciones que hacen a la criticidad ambiental de estas áreas es la presencia de diversas actividades industriales y empresas comerciales (como supermercados) que muchas veces no son compatibles con espacios residenciales y que vierten sus desechos cloacales en el río Paraná sin tratamiento previo (como es el caso de la planta industrial de hilandería "Tipoití", al norte; o la Industria cervecera Quilmes, al Sur).

En las imágenes siguientes se muestran fotografías satelitales de la Inundación de Enero-Febrero de 2014 y de un registro realizado durante recorridos por los barrios de la Zona Norte en los meses de junio y agosto de 2017.

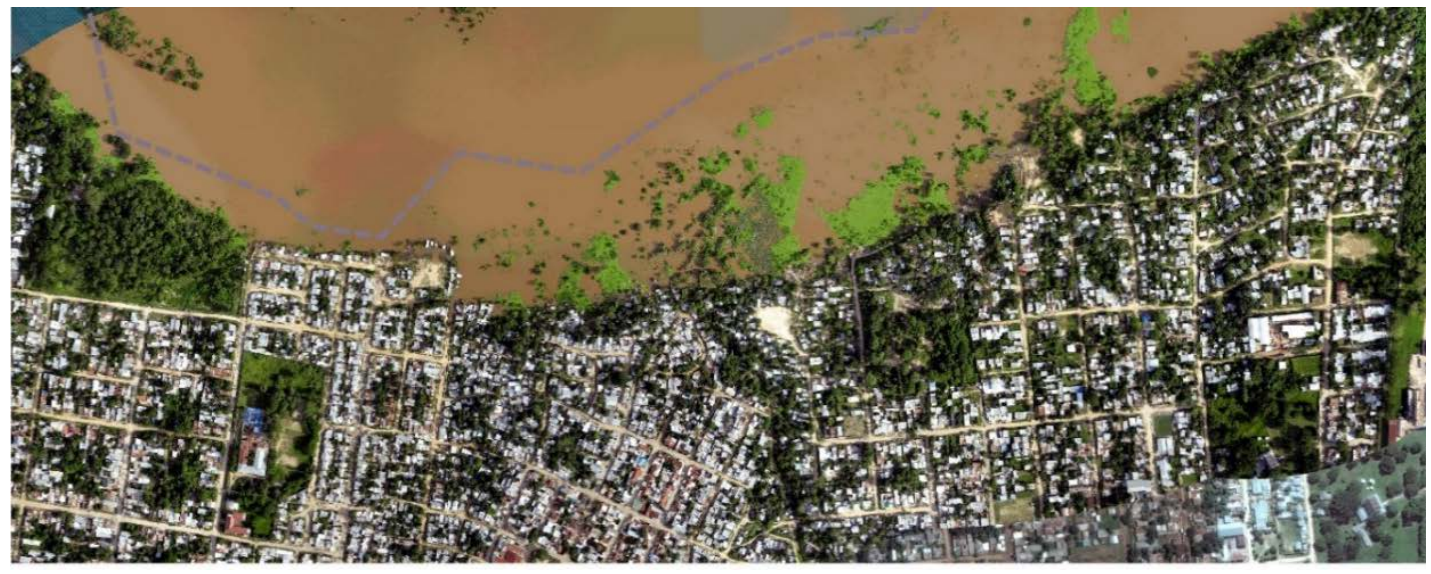

Imagen Satelital de Zona ribereña norte en período de Inundaciones 2015. Fuente: Secretaría de Planeamiento Urbano. Municipalidad de Corrientes. 

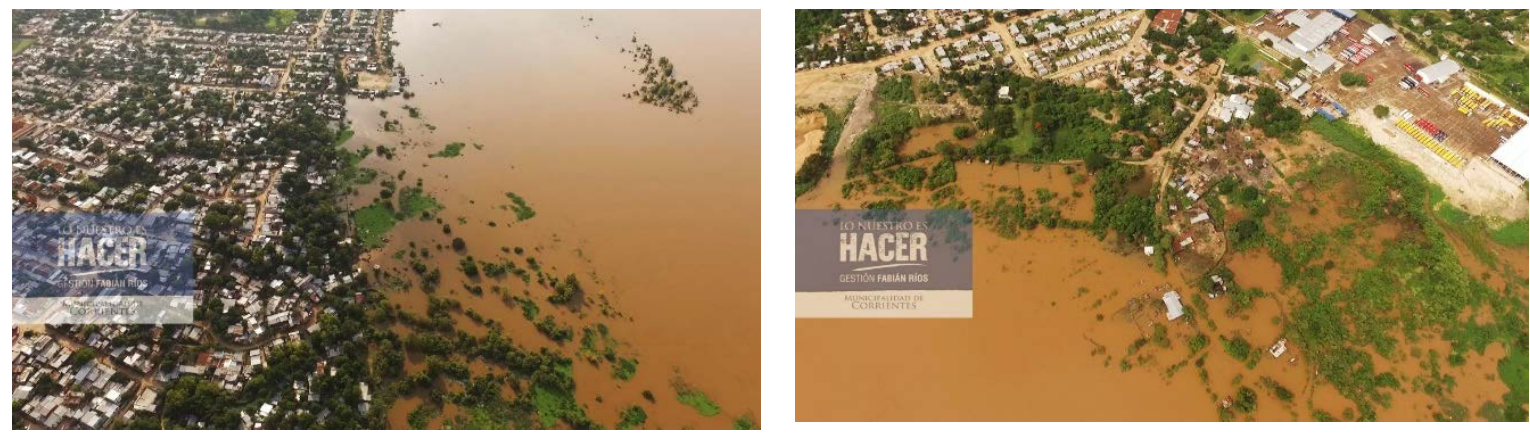

Imágenes tomadas con drone, diciembre 2015. Izq.: Costa Norte, As. Bañado Norte, Sol de Mayo, Anahí, Cichero. Drch.: As Santa Marta y Empresa ERSA. Fuente: Municipalidad de Corrientes.
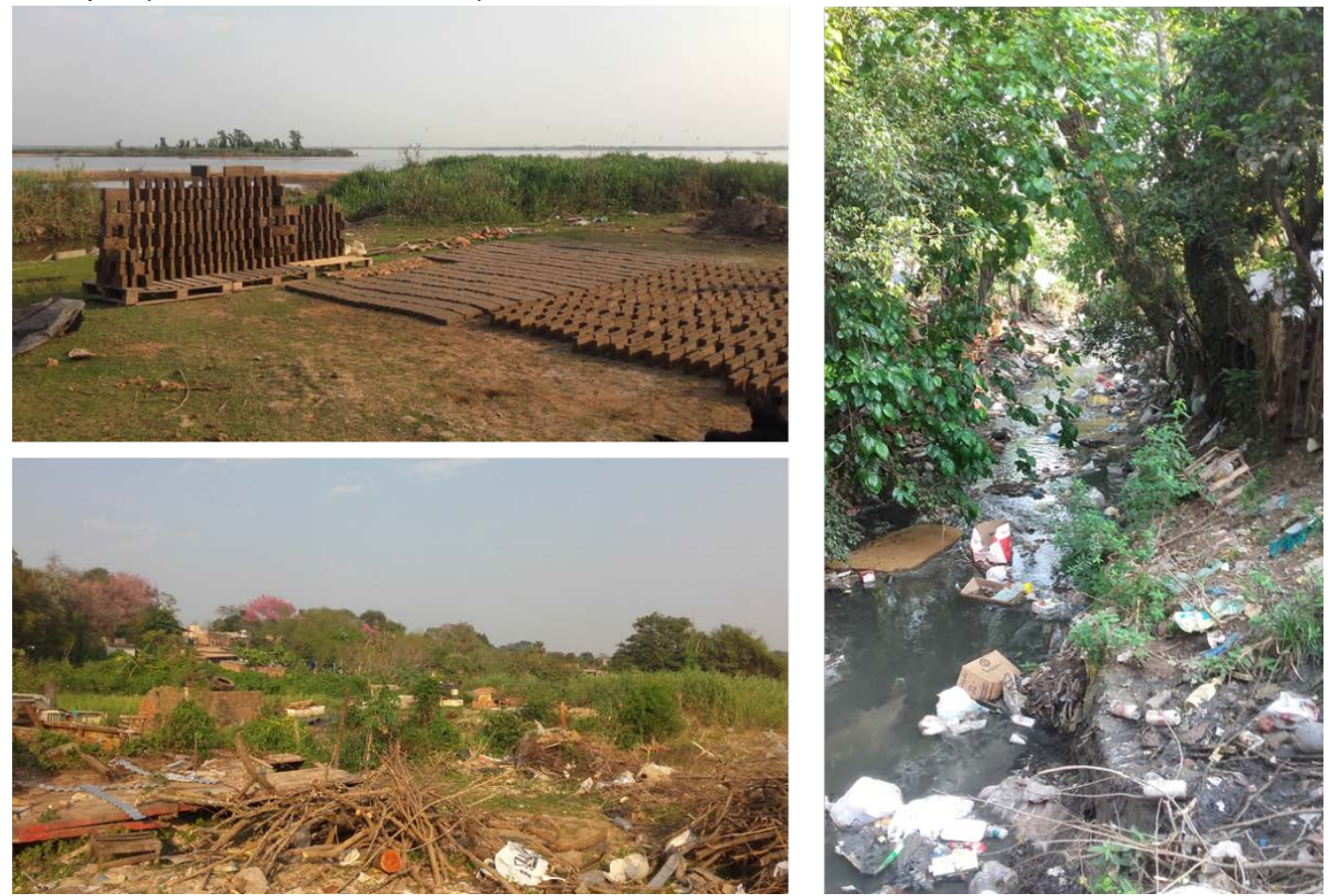

Registro fotográfico, Junio 2017. A la Izquierda; Ribera Norte, sector de olerías y pescadores; A la derecha: Arroyo Santo Domingo, límite entre Asentamientos: Quinta Ferré y Sol de Mayo. Fuente: Elaboración propia, 2017.

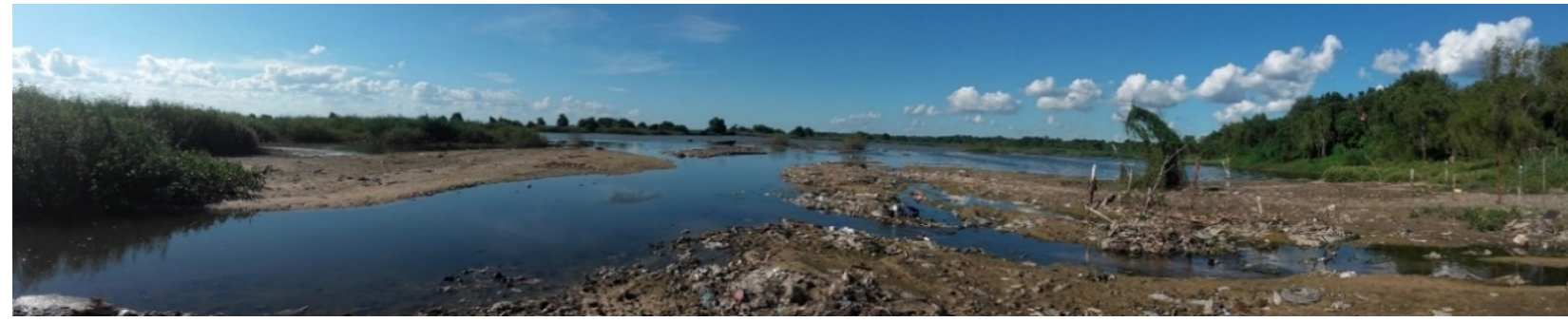

Fotografía del paisaje de Bañados tomadas en borde ribereño Norte, Barrio Canal 13. Fuente: Elaboración propia, 2017.

\subsection{Infraestructura básica: agua y cloacas}

Los servicios de agua y cloaca están vinculados a la paulatina expansión del área edificada, estando el área central completamente cubierta por ambos, desde donde se comienzan a observar discontinuidades e incompletitudes. Esto se observa de manera extrema en áreas informales de la costa donde las redes se interrumpen. La red de agua potable en la ciudad en general, se encuentra mucho más completa y es resuelta en la mayoría de los barrios populares de forma irregular y autogestionada, pagando muchas veces el municipio los consumos producidos a la empresa privada Aguas de Corrientes SA. Los desechos cloacales, 
en estas áreas, son vertidos en pozos ciegos de forma particular o muchas veces mediante redes autoconstruidas vertidas en los cursos de agua sin tratamiento.

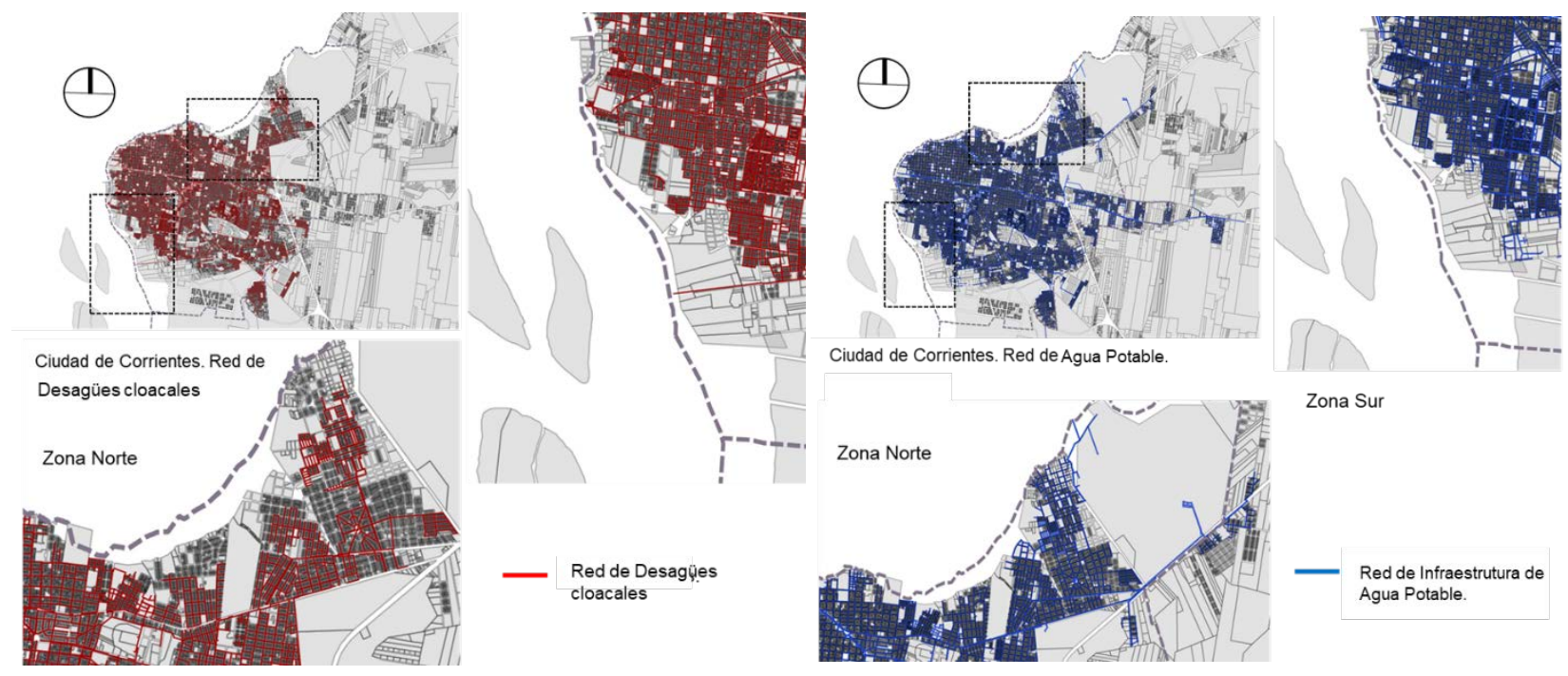

Izq. Infraestructura Red Cloacal Comparación Ciudad de Corrientes, Zona Norte y Zona Sur. Fuente: Elaboración propia en base a SIG municipal, 2017. Drcha. Infraestructura Red de Agua Potable. Comparación Ciudad de Corrientes, Zona Norte y Zona Sur. Fuente: Elaboración propia en base a SIG municipal, 2017.

\subsection{Conectividad}

El Área Norte en Corrientes presenta fuerte dependencia de la Av. Armenia uno de los ejes radiales que vinculan con el centro, pero la llegada a este eje en forma de "peine" no es homogénea pues existen importantes discontinuidades de la red, sobre todo al interior de los barrios por los cambios en las tramas, en las lógicas de producción estatal e informal y la incomplitud de la infraestructura. En el Área Sur la situación es de mayor criticidad aún pues no existe proximidad a ningún eje que garantice la continuidad y la comunicación con el resto del área metropolitana, las conexiones se dan de manera muy fragmentada y existen asentamientos que poseen una única calle de tierra que permite la circulación a otras vías de mayor jerarquía.

Al interior de los barrios informales aparecen nuevas formas de conexión, aquellos pasajes, puentes peatonales que vinculan áreas y construyen ciertas relaciones/división.

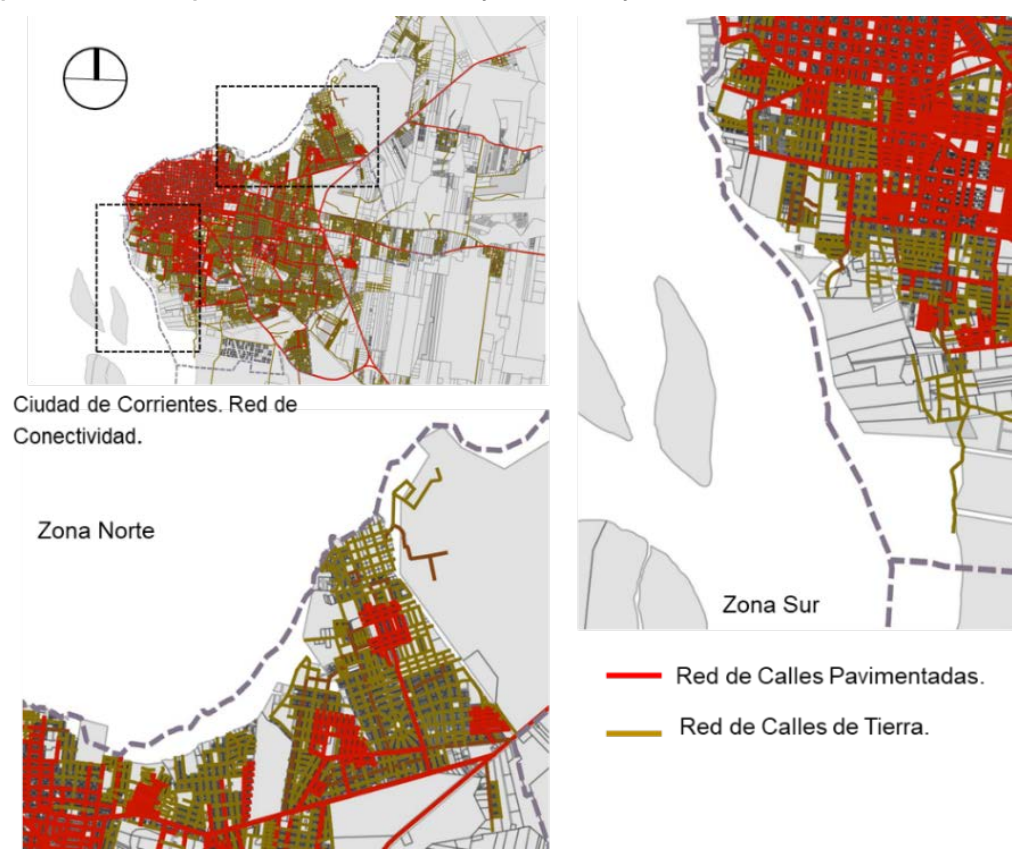

Red Viaria, calles pavimentadas y de tierras. Comparación Ciudad de Corrientes, Zona Norte y Zona Sur. Fuente: Elaboración propia en base a SIG municipal, 2017 

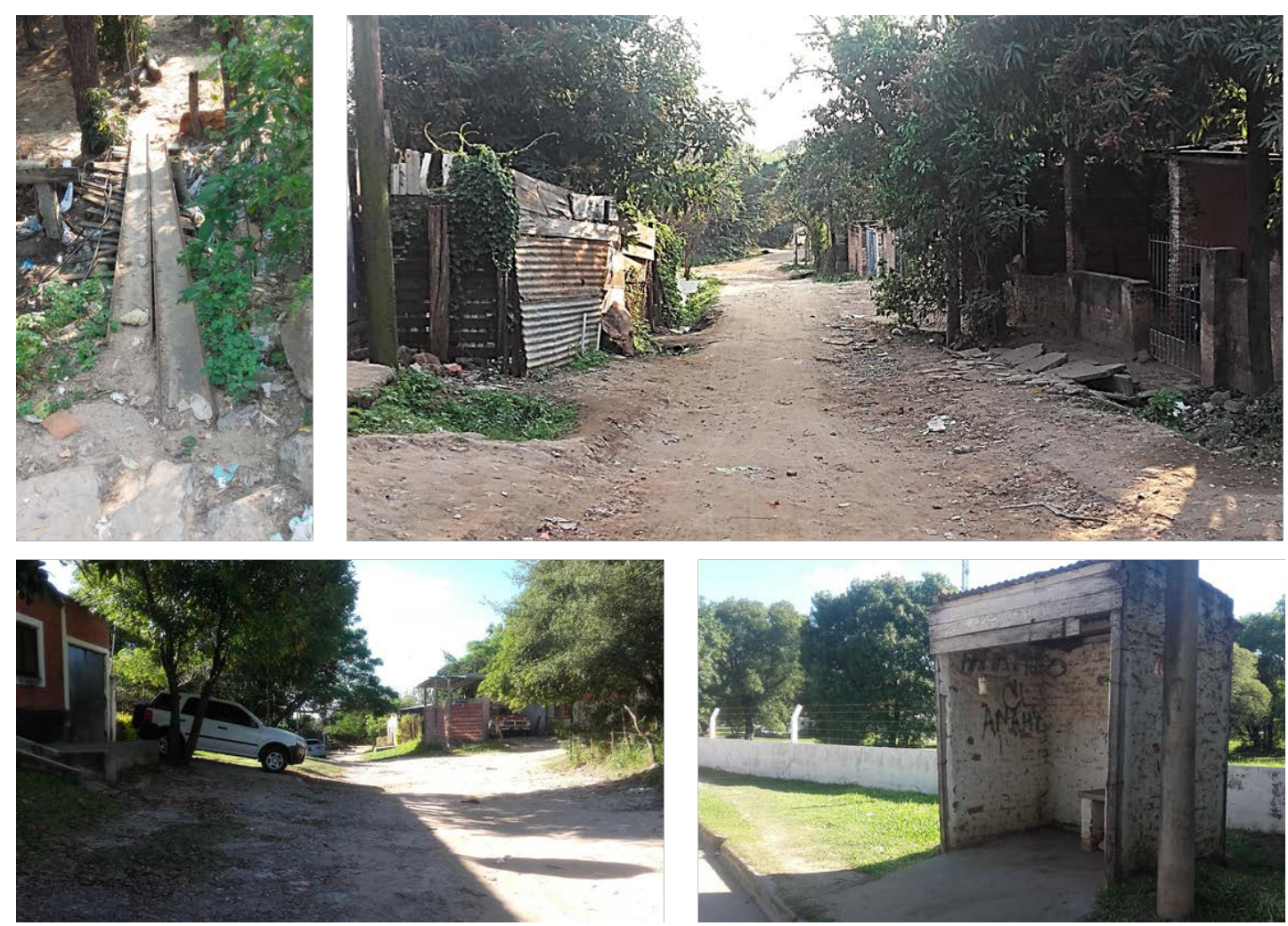

Registro fotográfico de calles y pasajes en Barrios del área Norte. Fuente: Elaboración propia, 2017.

\subsection{Espacio público}

En el caso de Corrientes, se cuenta con la identificación de los corredores o paseos lineales (como la Costanera), plazas y parques, que son categorizados como "espacios verdes" por parte del Municipio. Se puede reconocer que el área central presenta la mayor oferta de espacio público y también es la mejor cualificada. En el área central el borde del río constituye el espacio público lineal de mayor importancia, al que a su vez aparecen vinculados dos de los parques más relevantes de la ciudad (Camba Cuá y Mitre). El área central cuenta además con las plazas tradicionales de 1 ha distribuidas homogéneamente. Fuera de esta área existen plazas o espacios verdes vinculados a conjuntos habitacionales, algunos espacios vacíos utilizados por la comunidad barrial, pero existen áreas seriamente deficitarias. Los espacios públicos de la periferia en general no presentan las mismas dotaciones que los del área central y se encuentran seriamente afectados por la presencia de microbasurales.

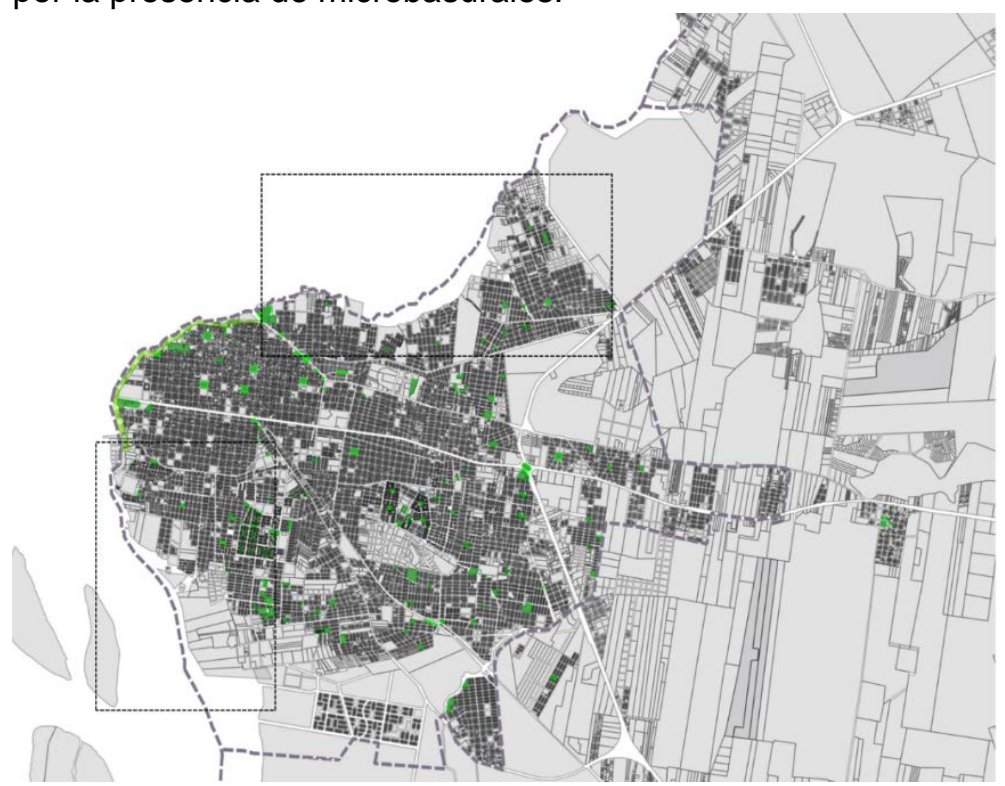

Distribución de espacios verdes públicos en la Ciudad de Corrientes. Fuente: Elaboración propia en base a SIG municipal, 2017. 


\subsection{Unidades Espaciales homogéneas.}

Este indicador hace referencia a sectores que son resultados de una forma específica de producción de suelo, agrupados en relación a características morfológicas concretas en las que predomina un tipo de trama (calles y manzanas); un tipo edificatorio y de ordenamiento espacial de la edificación; características generales de la urbanización y del espacio público; que tuvieron un mismo origen y que por lo general presentan determinadas características de localización y son habitados por un perfil socio-económico (Alcalá et al., 2016). Se distinguieron 5 unidades espaciales residenciales homogéneas (UERH): Ciudad tradicional (aquella que surge del tejido central), asentamientos informales, loteos privados (áreas de countries, tipo parque, clubes privados, etc), conjuntos habitacionales (de ordenamiento singular o de 50×100) áreas heterogéneas o mixtas (asentamientos informales con intervenciones del estado) y $\mathbf{2}$ Unidades Espaciales Especiales (UEHE) (Recintos de tipo comercial o industrial y grandes equipamientos urbanos, áreas rururbanas)

En el caso de las AUDC de Corrientes, no existen grandes contrastes socioeconómicos con excepción de la punta norte del AN, donde existe un loteo privado. En general predominan los asentamientos, los conjuntos habitacionales a partir de tramas ortogonales de menor tamaño, habitada por familias de clase baja o mediabaja. En estas AUDC las discontinuidades existen porque no están ajustadas las distintas tramas entre sí, por la presencia de accidentes naturales como los arroyos que desaguan perpendiculares al río y por la presencia de grandes recintos fabriles o empresariales.

A partir de este indicador es posible observar que existe una gran heterogeneidad en las unidades espaciales que aparecen en el territorio, dando muestra de diferentes formas de habitar y tipos de usos urbanos que coexisten, y los cuales son ámbito de estudio de esta investigación.



Disposición de Unidades Espaciales Homogéneas en la Ciudad de Corrientes, Comparación de áreas Norte y Sur. Fuente: Elaboración propia, 2017. 


\subsection{Algunos Patrones Urbanos identificados.}

A partir de lo observado es posible establecer una serie de patrones que se repiten. Por un lado, el aislamiento, como consecuencia de la "incomplitud" y la "suburbanización", la vulnerabilidad ambiental vinculada al riesgo hídrico, sumado a la ausencia de red cloacal; la homogeneidad socio-espacial que se observa en la proliferación de barrios informales en relación con el borde costero y que contribuye a la conformación de enclaves marginales con diversos conflictos socio-espaciales internos.

Si estudiamos las diferentes Unidades espaciales homogéneas (UEH), del área costera Norte, es posible observar una multiplicidad de situaciones, la trama urbana (que viene del área central) presenta discontinuidades espaciales en el tejido urbano por la presencia de conjuntos habitacionales y variaciones en la topografía (presencia de arroyos y desniveles), o límites vinculados a áreas internamente homogéneas como asentamientos informales, vacíos urbanos, recintos industriales; que contribuyen a procesos de fragmentación.

Se sostiene como supuesto preliminar que estas áreas son habitadas por población de clase baja o muy baja (en condiciones socioeconómicas similares), pero donde los patrones de segregación no son tan marcados, sino que juega un rol más importante la acción directa o indirecta de actores externos como el Estado y los límites presentes (físicos o simbólicos) que promueven estos procesos de fragmentación distintos.

El objetivo será verificar si se dan procesos de fragmentación, y las categorías o especificidades que la definen. Kozak (2010) nos ayuda a comprender la fragmentación desde cuestiones espaciales o físicas, definiéndola como una forma de organización en la que los límites duros, lo confinado y los obstáculos adquieren un rol central, un estado espacial de separación e inconexión que a menudo es acompañado de divisiones socio-económicas y/o étnicas. En este sentido, las discontinuidades urbanas a escala macro y micro, los cambios de trama, las grandes infraestructuras o barreras provocadas por grandes recintos o por un arroyo contaminado que divide dos barrios pueden llamarnos a reconocer este concepto, en tanto, como dice el autor conducen a estas formas de identidades restringidas y a la incapacidad de usar y atravesar el espacio, provocando procesos de exclusión. Y por otro lado, autores como Prévôt Schapira (2008) exponen que la fragmentación es un "fenómeno reconocible también en los intersticios de una sociedad polarizada, bajo la forma de micro-estrategias de distinción y de negociación sobre un fondo de polarización social y de política urbana intermitente y contradictoria." (p. 1), permitiéndonos, desde este lugar estudiar los procesos de fragmentación desde algunas políticas o acciones producidas a partir del Estado (como los programas habitacionales focalizados por el Instituto de Vivienda Provincial), las redes clientelares construidas, y siguiendo esta línea, la acción de grupos diferentes y su incidencia en el territorio.

\section{CASOS ANÁLOGOS}

Las áreas costeras aparecen en la literatura científica como un territorio en constante transformación, donde confluyen múltiples procesos de renovación urbana y valorización. Esto puede ser interesante para comprender las dinámicas que devienen de territorios de alto valor paisajístico, en contraste con las actuales condiciones del territorio de estudio y las tendencias del mercado.

Existe un sinnúmero de experiencias internacionales y argentinas en las que las intervenciones costeras (algunas incluso con otras intenciones) produjeron procesos de valorización, conformación de áreas exclusivas para sectores socioeconómicos altos, muchas caracterizadas por diseños estándar de componentes estéticos y funcionales de la modernidad, que produjeron en algunos casos la expulsión de los residentes históricos y la sustitución del paisaje anterior. En su mayoría pueden enmarcarse en la noción de Grandes Proyectos Urbanos (GPU) como Puerto Madero en Bs.As., Porto Maravilla en Río, las Obras complementarias a Yacyretá, como la Costanera de Posadas, la costa de Rosario e inclusive la Costa Sur en Corrientes. Las características e impactos de estos grandes proyectos son estudiados por autores como Cuenya (2009), quien expone que cada vez más son recurrentes estas estrategias desde los 90' dentro de las ciudades, que surgen a partir de iniciativas público-privadas debido al "influjo de la globalización", convirtiéndose en nodos estratégicos dentro de las ciudades.

Entre los estudios sobre los grandes proyectos de frentes costeros y sus efectos sociales, con tendencias a la valorización de los espacios urbanos y procesos gentrificantes, puede ser mencionada la trabajada por Brites (2008; 2016) que retoma el caso de las transformaciones acaecidas en Posadas (Argentina), a partir de las obras de infraestructura complementarias a la represa hidroeléctrica de Yacyretá, que debió proveer de defensas costeras a lo largo del río Paraná, rehabilitando amplios sectores urbanos y recomponiendo urbanísticamente a la ciudad. El conjunto de obras costeras dio lugar a la emergencia de la especulación inmobiliaria e inversión privada, así como a nuevas formas de desplazamientos con y sin acción directa del Estado. 
Por otro lado, la transformación de la ribera de Rosario (Santa Fé, Argentina), fue llevada adelante por la tesis de Galimberti (2015) "La reinvención del Río Procesos de transformación de la ribera de la Región Metropolitana de Rosario, Argentina". La investigación se centra en el estudio de la trama de interrelaciones sociales, económicas, políticas y ambientales existentes en los procesos de transformación de los frentes costeros contemporáneos, tomando como esta como caso de estudio. El frente es tomado como "laboratorio de análisis" por sus múltiples procesos complejos de transformación que se fueron dando en las metrópolis portuarias, conducido por la hipótesis de que la reinvención del río a través de la interpretación atenta de las reglas genéticas del lugar constituye el principal principio para producir un nuevo proceso de territorialización.

Existe una literatura amplia en nuestra región sobre la temática abordada, la cual será necesaria de estudiar para comprender las discusiones existentes. Sin embargo, no hay ningún estudio sobre la ribera periférica de Corrientes, caracterizadas a su vez, por constituirse como ámbitos de desconocimiento para la gestión urbana municipal, fuera del alcance de la planificación, y que frente a su heterogeneidad tanto como sus condiciones de vulnerabilidad, detentan una gran complejidad y múltiples singularidades que son necesarias de atender.

\section{ALGUNAS REFLEXIONES Y NUEVAS PESQUISAS A ABORDAR.}

El espacio urbano parece cada vez más, conformarse por fragmentos en su disposición e interrelación en el territorio, que aun cuando en conjunto plantean una misma localización, similares condiciones de accesibilidad, disposición de equipamientos y servicios comunes, etc., en su interior, pueden presentar marcados contrastes no sólo físicos sino también de diferenciación social, y condiciones de inequidad urbana y desigualdad en las oportunidades de ejercicio del derecho a la ciudad. (Barreto y otros, 2016). Así mismo, se constituyen identidades autorreferenciales, construidas en cada fragmento, donde en las interacciones, prácticas y movilidad de los grupos, se construyen límites virtuales y físicos que contribuyen a los conflictos y la exclusión.

Los procesos sociales y la forma espacial, según Harvey (1973), aparecen frecuentemente disociados en los estudios urbanos, diferenciándose de aquellas disciplinas con mayor conciencia o imaginación sociológica, que carecen de conciencia espacial; o al revés, aquellas disciplinas que estudian el espacio y carecen de conciencia sociológica (entre esta se pueden encontrar a gran parte de los planificadores de la ciudad). Este divorcio es frecuente, contradictorio y limitado para conocer y transformar aquello que es entendido como problemático. Por esto, se propone un abordaje dialéctico en el cual la verificación no puede estar separada de la práctica social. Esto es mencionado como línea epistemológica a seguir, ya que en esta etapa inicial será necesario avanzar en el estudio de teorías actuales que permitan considerar la relación estructural que tienen los fenómenos globales y locales en el desarrollo de los órdenes urbanos emergentes en nuestras ciudades. Nociones tales como segmentación y desigualdad (Davis, 1991; Negri y Hardt, 2002), fragmentación (Marcuse, 1995; Kozak, 2010; Prevot Shapira, 2008), segregación, marginalización y guetización (Touraine, 1998; Wacquant, 2001), dualización (Castells, 1997; Sassen, 1998); homogeneidad / heterogeneidad, (Hannerz, 1992, 1998), etc. (Cit. En Barreto, et al., 2016); que acontecen en el contexto de la ciudad post-fordista, las tendencias de la globalización, el sistema capitalista, los procesos de terciarización y metropolización de las ciudades, etc.; pero donde tendrá relevancia el trabajo de campo que aborde las formas actuales de construcción comunitaria de estas otras costas. Si bien no se llegará a trabajar en un enfoque constructivista, por la multiplicidad de actores que se identifican, se buscará (a partir de estas diferentes escalas de abordajes) hacer una descripción sobre las realidades de estas costas otras en relación a la dinámica social del espacio urbano.

Encontramos en las franjas ribereñas de Corrientes situaciones ignoradas, desvinculadas de la planificación histórica de actores hegemónicos. Las condiciones de "criticidad urbana" se definen por la interrelación de aspectos que se combinan y potencian mutuamente, esto implica una serie de derechos a estudiar y defender desde ciertos parámetros de urbanidad; lógicas comunitarias a comprender (reivindicar y respetar) desde la mirada propia de quienes habitan esta ciudad; y amenazas a prever, provenientes de actores con fines netamente económicos, egoístas en sus modos de hacer ciudad.

La integración física, territorial y social solo puede darse escapando de las formas de actuación guiadas por lógicas especulativas y hegemónicas que promueven la conformación de enclaves de bienestar socioeconómicos y la profundización de los escenarios de exclusión. Sera necesario abordar los sectores heterogéneos de la ciudad, complejos en sus diferentes escalas, en donde se perciben múltiples conflictos por el espacio, para lograr interpretar y repensar la localización de estas comunidades, la movilidad social y el intercambio funcional. Reconocer la identidad local, los procesos comunitarios y el valor patrimonial del territorio, se consideran como aspectos claves para superar contradicciones. 
A su vez será importante, introducir nociones provenientes del derecho civil, ambiental y administrativo; como por ejemplo: la concepción de la función social de la propiedad, principios ambientales, el Derecho a la Ciudad desde su contribución como parámetro de evaluación de los conflictos urbanos (Gargantini et al., 2016) y diferentes instrumentos de gestión urbano-ambiental, de participación de la población involucrada que permitan comprender las nuevas experiencias de hacer ciudad desde una perspectiva de derechos. (Reese, 2011) Si bien el espacio público aparece como un objeto a atender y a promover, es una temática urbana que exige un posicionamiento ideológico sin trivialidades. Se deben prever los procesos especulativos, expulsivos y gentrificantes de la costa, tratándose de consecuencias negativas observados en otros proyectos urbanos de espacios públicos. Es necesario reflexionar sobre los discursos de planificación y los intereses de actores hegemónicos; aprendiendo de los procesos "no deseados" de las intervenciones urbanas costeras o waterfronts, como ser: la conformación de productos estándar de ciudad, la valorización no controlada del suelo, la homogeneización de usos o niveles socio-económicos en el espacio, la privatización de la costa, la expulsión conducida, la gentrificación, la fragmentación urbana.

Como se mencionó antes, la importancia de esta temática radica en que no existen antecedentes o estudios realizados en la ciudad de Corrientes. Los bordes costeros fuera del área central son territorios marginales, donde los procesos de transformación, hasta el momento, son temporalmente más graduales, de la mano de la autoconstrucción popular, el mercado informal y en algunos barrios por la acción focalizada del Estado. Son muchas veces observadas desde la distancia como grandes territorios despoblados, reflotados por diferentes partidos políticos como parte de propuestas electorales (este es el caso de zona norte) o como parte de los planes de crecimiento de la ciudad, a partir del Máster Plan de Santa Catalina, en zona sur. Se propone en estos discursos "diseñar Corrientes de cara al Paraná", "revalorizar áreas" con grandes avenidas, paseos, edificios. Estas propuestas son acompañadas muchas veces por organizaciones vecinales involucradas.

Estas organizaciones (como el caso de la Red Vecinal Zona Norte) que accionan en el territorio y están constantemente activas en la búsqueda de mejorar las condiciones de estas áreas, son actores claves en el proceso para acceder a diferentes lecturas del territorio entendiendo las tramas de relación de los actores.

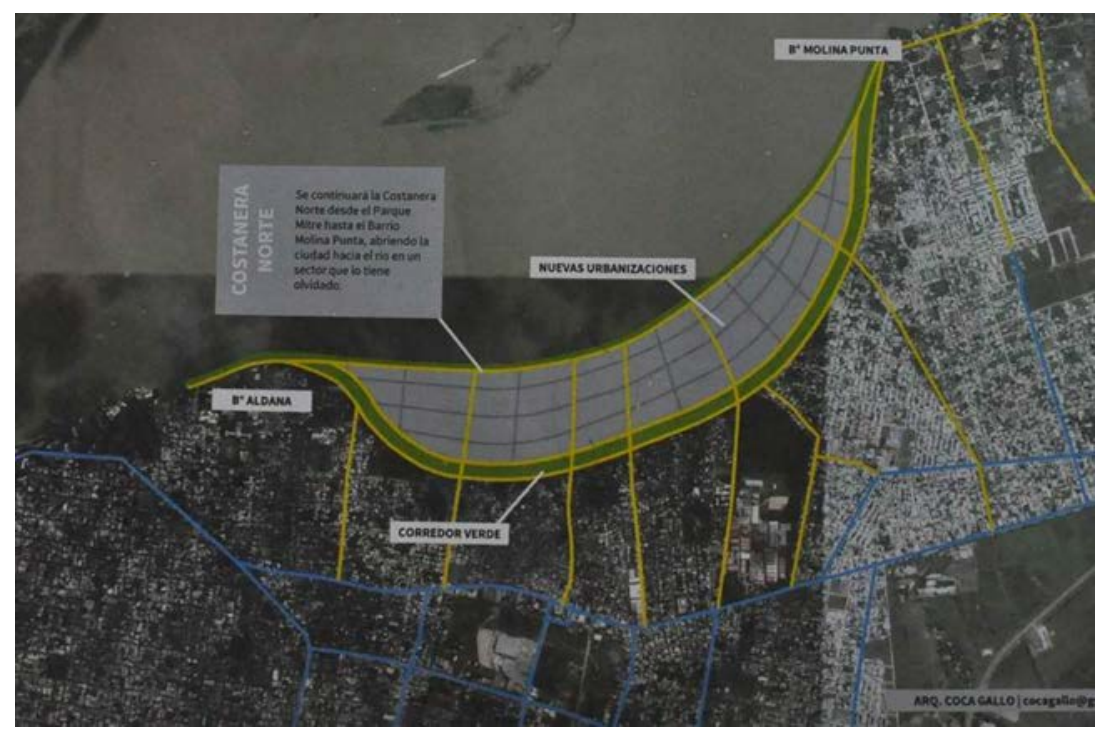

Imagen publicada en el Diario Época: Nuevo Proyecto de Costanera Norte. Fuente: pág. Web: http://diarioepoca.com/802049/presentaron-ambicioso-proyecto-integral-para-costanera-norte/ y http://diarioepoca.com/665504/nuevointento-para-la-construccion-de-la-costanera-norte-en-la-capital/. (consultada el 20/2/2018)

Por último, nos gustaría decir que el hilo de esta investigación surge de un conjunto de preguntas sobre ¿cómo se transforma esta realidad? ¿es posible consolidar en los bordes costeros los asentamientos informales que hoy existen, respetar el arraigo de su población al lugar, reducir las condiciones de vulnerabilidad hídrica y socioeconómica y mejorar su integración a la ciudad sin poner en riesgo las posibilidades de mantener como lugar de residencia las áreas más codiciadas por el mercado inmobiliario? Desde la acción urbanística en el espacio público ¿es posible propiciar el mejoramiento barrial de estos asentamientos y su integración plena al tejido urbano? ¿Qué instrumentos o herramientas serán necesarios promover para permitir una visión de carácter social inclusivo en la planificación y distribución del suelo urbano? 


\section{BIBLIOGRAFÍA PRINCIPAL}

ALCALÁ, L. et al. (2016) Patrones Urbano-Ambientales de Configuración Territorial en el Gran Resistencia. XXXVI Encuentro de Geohistoria Regional (ENGEO). Resistencia, Chaco. Publicado en Actas digitales ISBN 978-987-4450-00-5 (297-310).

ALCALÁ, L.; RUS, F. (2017) Áreas Urbanas Deficitarias Críticas en Territorios con Riesgo Hídrico. Análisis comparado de situaciones en las ciudades de Resistencia y Corrientes. I V Workshop de la RIDOT y VI Seminario Internacional de Ordenamiento Territorial. Mendoza, Octubre 2017. (Aceptado para su publicación)

ALCALÁ, Laura; et al. (2018) Caracterización Urbano Ambiental de una selección de áreas periféricas del Gran Resistencia. Revista ADNea (Aceptado para su publicación) Facultad de Arquitectura y Urbanismo, UNNE, Resistencia, Chaco.

AUYERO, J.; SWISTUN, D. (2008) Inflamable. Estudio del Sufrimiento ambiental. $1^{\mathrm{a}}$ Ed. Paidós. Buenos Aires.

BARRETO, M; et al. (2014) Áreas urbanas deficitarias críticas como unidades de interpretación y abordaje de los nuevos territorios periurbanos conducir las transformaciones urbanas. un debate sobre direcciones, orientaciones, estrategias y políticas que modelan la ciudad futura. Lugar: La Plata; Argentina, 2014; p. 1211 $-1223$

BONFIL BATALLA, Guillermo (1998) "Pensar nuestra cultura" Alteridades, vol. 8, núm. 16, julio-diciembre, 1998, pp. 177-178- Universidad Autónoma Metropolitana Unidad Iztapalapa. Distrito Federal, México

BOURDIEU, Pierre (1999) Efecto de lugar. En: Bourdieu, Pierre (1999) La miseria del Mundo, FCE, Buenos Aires.

BRITES, W. (2016) Grandes proyectos y sus efectos sociales. Tendencias a la sustitución social en espacios urbanos revalorizados [en línea] Fecha de consulta: 20-12-17. En: ACE: Architecture, City and Environment = Arquitectura, Ciudad y Entorno, 11 (32): 13-32, 2016. DOI: 10.5821/ace.11.32.3964. ISSN: 1886-4805.

CONTRERAS, I; FANTÍN, A. (2015) El riesgo de la población a inundaciones por lluvias como consecuencia de la dinámica de expansión urbana sobre paisajes anegadizos. El caso de la ciudad de Corrientes (Argentina). Folia Histórica del Nordeste. № 23. IIGHI - IH- CONICET/UNNE - (p. 97-112) Resistencia, Chaco, julio 2015.

CORBOZ, A. (1983) El territorio como palimpsesto. En: Martín Ramos. Lo urbano en 20 autores contemporáneos. Barcelona: Ediciones UPC, 2004.

DUHAU, Emilio; GIGLIA, Ángela (2004). Conflictos por el espacio y orden urbano. En Estudios Demográficos y urbanos, mayo -agosto, no 56 . Colegio de México. México D.F.

Fuentes electrónicas:

GALIMBERTI, CECILIA INÉS (2015) La reinvención del Río. Procesos de transformación de la ribera de la Región Metropolitana de Rosario, Argentina. Tesis Doctoral. $1^{\mathrm{a}}$ ed. - Rosario: UNR Editora. Editorial de la Universidad Nacional de Rosario. Facultad de Arquitectura, Planeamiento y Diseño. A\&P. 2015-

GARGANTINI Daniela; et al. (2016) Tierra de conflictos: conflictos urbanos y violaciones al derecho a la ciudad en Córdoba capital / - 1a ed. - Córdoba: EDUCC - Editorial de la Universidad Católica de Córdoba, 2016.

GONZÁLEZ, S; TORCHIA, N.; VIAND, J. (2015) Vulnerabilidad asociada a la ocupación de terrenos en áreas inundables. En "Inundaciones Urbanas y Cambio Climático. Recomendaciones para la gestión". (p. 45-47).

HARVEY, D. (1973) “Urbanismo y Desigualdad Social”. Ed. Siglo XXI de España Editores, 1977.

INFRAESTRUCTURA DE DATOS ESPECIALES (GIS) de la Municipalidad de Corrientes. Pagina Web: http://gis.ciudaddecorrientes.gob.ar/ (Consulta: Julio de 2017)

KOZAK, D. (2010) Fragmentación Urbana y Neoliberalismo Global. En: Pradilla E., ed. 'Ciudad Compacta y Ciudad Dispersa', México DF: Universidad Autónoma Metropolitana Xochimilco y Miguel Angel Porrúa Editor.

LOBATON, S. B.; HERNANDEZ; J. M. (2014) Perspectivas sobre el paisaje. Universidad Nacional de Colombia (Sede Bogotá). Facultad de Ciencias Humanas: Jardín Botánico José Celestino Mutis, 2014. Incluye referencias bibliográficas 486 p., il. - (Biblioteca abierta. Perspectivas ambientales)

LUNGO, M. Y SMOLKA, M. (2005) Suelo y grandes proyectos urbanos: La experiencia latinoamericana. Publicación Land Lines. En: Perspectivas urbanas: Temas críticos en políticas de suelo de América Latina. Lincoln Institute of Land Policy. 
MARCUSE, P. (1989) Dual city: a muddy metaphor for a quartered city. International Journal of Urban and Regional Research. Vol. 13 (4), pp. 697-708.

MERA, Gabriela (2014) De la Localización a la Movilidad: Propuestas teórico-metodológicas para abordar la segregación urbana. Cuaderno Urbano. Espacio, Cultura, Sociedad - Vol. 17 - N. ${ }^{\circ} 17$ (Noviembre de 2014).

MUNICIPALIDAD DE CORRIENTES. (2013) Plan de Santa Catalina y Reforma del Código Municipal de Planeamiento Urbano - Informe I Parte - Diagnóstico de la Ciudad de Corrientes. Programa de Fortalecimiento Institucional de la Subsecretaría de Planificación Territorial de la Inversión Pública.

MUNICIPALIDAD DE CORRIENTES. (2016) Código de Planeamiento Urbano. Ord. № 1071 (Publicación Original) Boletín Municipal № 272 Corrientes, 7 de julio de 1988. Tercer texto actualizado y ordenado al 31/05/16.

PINTOS, P. (2014) Paisajes que ya no serán. Acumulación por desposesión e hibridación pseudo-urbana de humedales en la cuenca baja del río Luján, Argentina. Biblioteca Abierta. Colección General, serie Perspectivas Ambientales. Universidad Nacional de Colombia, sede Bogotá.

PRÉVÔT-SCHAPIRA, M.; PINEDA, R. (2008) Buenos Aires: la fragmentación en los intersticios de una sociedad polarizada. Revista Eure, Vol. XXXIV, № 103, pp. 73-92, diciembre 2008

RUS, María Florencia (2017) Focalización territorial en sectores con Riesgo Hídrico en la Ciudad de Corrientes. Las Áreas ribereñas vulnerables como Zonas Prioritarias para la Gestión Pública. Jornadas de Comunicaciones Científicas y Tecnológicas, Facultad de Arquitectura y Urbanismo, UNNE. (Artículo en revisión)

RUTH SAUTU (2003) Todo es Teoría. Objetivos y Métodos de Investigación. Ed. Lumiere. Buenos Aires, 2005.

TECHO OSC. Centro de Investigaciones Sociales (CIS) (2015) "Relevamiento de Asentamientos Informales (RAl) 2015" Web: http://mapaasentamientos.com.ar/ (Consulta: mayo de 2017)

VALENZUELA, Ma. Victoria (2008) Paisaje Natural y Cultural en la Ciudad de Corrientes. CEHAUUNNE/FAU. Corrientes. 